\title{
Flexible sample cell for real-time GISAXS, GIWAXS and XRR: design and construction
}

\author{
M. Berlinghof, C. Bär, D. Haas, F. Bertram, S. Langner, A. Osvet, A. \\ Chumakov, J. Will, T. Schindler, T. Zech, C. J. Brabec and T. Unruh
}

J. Synchrotron Rad. (2018). 25, 1664-1672

\section{IUCr Journals CRYSTALLOGRAPHY JOURNALS ONLINE}

Copyright (C) International Union of Crystallography

Author(s) of this paper may load this reprint on their own web site or institutional repository provided that this cover page is retained. Republication of this article or its storage in electronic databases other than as specified above is not permitted without prior permission in writing from the IUCr.

For further information see http://journals.iucr.org/services/authorrights.html 


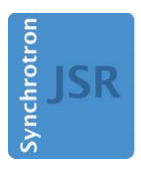

ISSN 1600-5775

Received 26 July 2018

Accepted 17 September 2018

Edited by I. Lindau, SLAC/Stanford University, USA

Keywords: in situ; GIWAXS; GISAXS; XRR; thin film.

Supporting information: this article has supporting information at journals.iucr.org/s

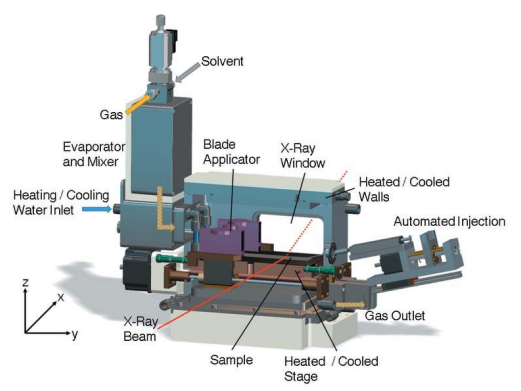

(C) 2018 International Union of Crystallography

\section{Flexible sample cell for real-time GISAXS, GIWAXS and XRR: design and construction}

\author{
M. Berlinghof, ${ }^{a}$ C. Bär, ${ }^{\text {a }}$ D. Haas, ${ }^{\text {b }}$ F. Bertram, ${ }^{\text {b }}$ S. Langner, ${ }^{c}$ A. Osvet, ${ }^{c}$ \\ A. Chumakov, ${ }^{\text {f }}$. Will, ${ }^{\mathrm{a}, \mathrm{e}}$ T. Schindler, ${ }^{\mathrm{a}}$ T. Zech, ${ }^{\mathrm{a}}$ C. J. Brabec ${ }^{\mathrm{c}, \mathrm{d}}$ and T. Unruh ${ }^{\mathrm{a}, \mathrm{e} *}$
}

${ }^{a}$ Institute for Crystallography and Structural Physics (ICSP), Friedrich-Alexander-University Erlangen-Nürnberg (FAU), Staudtstraße 3, 91058 Erlangen, Germany, b DESY Photon Science, Notkestraße 85, 22607 Hamburg, Germany, 'Institute Materials for Electronics and Energy Technology (i-MEET), Friedrich-Alexander-University Erlangen-Nürnberg (FAU), Martensstraße 7, 91058 Erlangen, Germany, 'Bavarian Center for Applied Energy Research (ZAE Bayern), Immerwahrstraße 2, 91058 Erlangen, Germany, ${ }^{\mathbf{e} C e n t e r ~ f o r ~ N a n o a n a l y s i s ~ a n d ~ E l e c t r o n ~ M i c r o s c o p y ~(C E N E M), ~}$ Friedrich-Alexander-University Erlangen-Nürnberg (FAU), Cauerstraße 6, 91058 Erlangen, Germany, and 'The European Synchrotron Radiation Facility (ESRF), 71 Avenue des Martyrs, CS40220, 38043 Grenoble Cedex 9, France. *Correspondence e-mail: tobias.unruh@fau.de

Since the properties of functional materials are highly dependent on their specific structure, and since the structural changes, for example during crystallization, induced by coating and annealing processes are significant, the study of structure and its formation is of interest for fundamental and applied science. However, structure analysis is often limited to ex situ determination of final states due to the lack of specialized sample cells that enable real-time investigations. The lack of such cells is mainly due to their fairly complex design and geometrical restrictions defined by the beamline setups. To overcome this obstacle, an advanced sample cell has been designed and constructed; it combines automated doctor blading, solvent vapor annealing and sample hydration with real-time grazing-incidence wide- and small-angle scattering (GIWAXS/GISAXS) and X-ray reflectivity (XRR). The sample cell has limited spatial requirements and is therefore widely usable at beamlines and laboratoryscale instruments. The cell is fully automatized and remains portable, including the necessary electronics. In addition, the cell can be used by interested scientists in cooperation with the Institute for Crystallography and Structural Physics and is expandable with regard to optical secondary probes. Exemplary research studies are presented, in the form of coating of $\mathrm{P} 3 \mathrm{HT}: \mathrm{PC}_{61} \mathrm{PM}$ thin films, solvent vapor annealing of DRCN5T:PC ${ }_{71} \mathrm{BM}$ thin films, and hydration of supported phospholipid multilayers, to demonstrate the capabilities of the in situ cell.

\section{Introduction}

In the recent decade, grazing-incidence X-ray scattering and $\mathrm{X}$-ray reflectivity have become crucial techniques for the characterization of novel thin-film materials, like organic photovoltaics (OPVs) (Pröller et al., 2017; Sanyal et al., 2011; Kassar et al., 2016; Wang et al., 2010; Güldal et al., 2017; Müller-Buschbaum, 2014), molecular self-assembly at interfaces (Tang et al., 2005; Doshi et al., 2003; Steinrück et al., 2015; Kirschner et al., 2017) and buried nanostructures and layers (Ferrarese Lupi et al., 2017; Will et al., 2018; Jiang et al., 2011). With the increasing flux and brilliance of synchrotron X-ray sources and of state-of-the-art laboratory-scale instruments, time-resolved in situ and operando studies became feasible. In such studies further insight into structure formation processes in thin films can be achieved upon drying and crystallization (Pröller et al., 2015; Kassar et al., 2016), annealing (Manley et al., 2017; Günkel et al., 2015), hydration (Kamata et al., 2014) etc. To study those processes with grazing-incidence wide- 
angle X-ray scattering (GIWAXS), grazing-incidence smallangle X-ray scattering (GISAXS) and X-ray reflectivity (XRR) at beamlines, quite complex sample cells, which need to be automatized, are required. Thus, some specialized cells have been developed for in situ coating, e.g. doctor blading, spray coating, roll-to-roll printing etc., by the authors of this paper (Kassar et al., 2016; Güldal et al., 2016a) and by others (Sanyal et al., 2011; Wang et al., 2010; Roth, 2016; Gu et al., 2016; Liu et al., 2015). Many of these run under ambient conditions. Other researchers have built sample cells specialized for thermal annealing (Lilliu et al., 2012) or sample hydration (Kučerka et al., 2005; Katsaras \& Watson, 2000; Wernecke, 2016). It is evident that there is a significant scientific demand for suitable sample environments. Therefore, we have designed and constructed a flexible setup which allows for in situ and real-time studies of drying kinetics after doctor blading of thin films, of solvent vapor annealing (SVA) of thin films and of hydration of samples. The fully automated and portable setup is designed for use at beamlines and laboratory instruments. A similar approach was realized by Pröller et al. who constructed a sample cell for in situ studies of slot-die coated samples using GIWAXS/GISAXS in combination with optical spectroscopy (Pröller et al., 2017). In contrast to this approach, our setup features a different but very flexible coating technique (doctor blading) since doctor blading is close to industrial roll-to-roll printing processes, and still provides the necessary flexibility and reliability for fundamental research (Krebs, 2009; Søndergaard et al., 2012; Brabec \& Durrant, 2008). In addition, our cell allows for very homogeneous and stable temperature control, and is designed to reach relative humidities close to $100 \%$ during hydration. Moreover, this cell is available to the scientific community. We openly encourage interested scientists to use our cell in cooperation with the Institute for Crystallography and Structural Physics during beam times. In addition, the technical drawings and specifications for duplication of the cell can be provided. Some basic technical drawings are presented in $\S \mathrm{S} 1$ of the supporting information.

After a technical description of the cell in $\$ 2$, scientific examples will be presented in $\S 3$ to demonstrate the capabilities of the in situ cell. Each example focuses on different key features and techniques usable with this cell. In the case of OPVs, the power conversion efficiency (PCE) is strongly dependent on the molecular structure of the bulk heterojunction thin films. Time-resolved GIWAXS studies provide detailed insight into the structure formation and drying kinetics needed for the design of efficient printed solar cells. In this context, the first example is the time-resolved study of the structure formation of $\mathrm{P} 3 \mathrm{HT}: \mathrm{PC}_{61} \mathrm{BM}$ after doctor blading (§3.1). A P3HT: $\mathrm{PC}_{61} \mathrm{BM}$ solution was doctor bladed as it is one of the most studied organic photoactive materials and is an ideal reference sample. Another common tool used for optimizing the structure of the photoactive layer with regard to efficiency is to increase its crystallinity by post-processing the device using SVA (Fuwen et al., 2018; Min et al., 2016, 2017; $\mathrm{Hu}$ et al., 2014; Sun et al., 2014). In $\$ 3.2$ the SVA-induced crystallization of the small molecule photoactive material
DRCN5T:PC ${ }_{71} \mathrm{BM}$ is presented. Solid supported multilayers of phospholipids like DMPC are commonly used as model systems for membranes of biological cells used in life sciences and pharmaceutical research (Teixeira et al., 2012; Peetla et al., 2009). In order to match the conditions found in living organisms these multilamellar systems need to be hydrated. Structural changes of the DMPC multilayers during the hydration process are presented in the last example of this article (\$3.3).

\subsection{Methodology for sample annealing and hydration}

In many cases, SVA is performed by pipetting the solvent manually in a petri dish followed by incubation (Sun et al., 2014; Min et al., 2016, 2017). It is evident that this kind of annealing procedure is not suited for time-resolved reproducible measurements. For this purpose the in situ cell can be pumped constantly with solvent saturated gases. The flow of the saturated gases is controlled by mass flow controllers, which allow for a remarkably high reproducibility. Moreover, they allow a precise adjustment of the solvent humidities from $0 \%$ up to a saturation of close to $100 \%$. Thus, the annealing speed and degree of annealing can be controlled accurately by changing the vapor concentration inside the gas phase.

The hydration of thin films is often achieved by the absorption of water from the gas phase with close to $100 \%$ relative humidity (Kučerka et al., 2005; Nagle \& TristramNagle, 2000). Placing the films in a closed cell next to a water reservoir with a high surface-to-volume ratio is a common approach (Wernecke, 2016; Katsaras \& Watson, 2000; Jing et al., 2009; Kučerka et al., 2005). In contrast to our in situ cell, a constant stream of air saturated with water is pumped through the cell. Analogous to SVA, this allows for precise control of the degree and speed of hydration.

\section{Technical description}

The sample cell has been designed to meet spatial restrictions of typical laboratory instruments and especially synchrotron instruments, like the High Resolution Diffraction Beamline P08 at PETRA III (DESY) (Seeck et al., 2012). Owing to its compact design (see Fig. 1 and Table 1), the whole setup can be installed easily on various instruments. Exemplary photographs of the in situ cell installed at several instruments are presented in $\S S 2$ of the supporting information and a summary of the specifications described in the paragraphs below is given in Table 2.

The gas-tight sample cell is made of aluminium. The sample stage inside the cell is made of copper, which enables a stable and homogeneous temperature at the sample position. The stage is covered by a flat $4 \mathrm{~mm}$-thick glass-ceramics pane (NEXTREMA 712-3N; Schott AG, Mainz, Germany), which is perfectly suited as a base plate for coating experiments. The cell features up to triple-pane windows (Nalophan; Kalle $\mathrm{GmbH}$, Wiesbaden, Germany) for the incoming and outgoing X-ray beam to increase thermal isolation and prevent condensation of vapors at elevated temperatures inside the 
Table 1

Dimensions and weight of the in situ cell.

Dimensions of cables and hoses are not included in the tabulated values. The injection system and the controlled evaporator mixer can be removed, with the corresponding dimensions being denoted as core. The width, length and height of the cell are labeled as $x, y$ and $z$, respectively (see Fig. 1).

\begin{tabular}{lcccll}
\hline & Total & Injection & Core & $\begin{array}{l}\text { Front } \\
\text { window }\end{array}$ & $\begin{array}{l}\text { Back } \\
\text { window }\end{array}$ \\
\hline$x(\mathrm{~mm})$ & 160 & 50 & 160 & & \\
$y(\mathrm{~mm})$ & 491 & 187 & 214 & 40 & 97 \\
$z(\mathrm{~mm})$ & 407 & & 182 & 20 & 52 \\
Mass $(\mathrm{kg})$ & 15 & & & & \\
\hline
\end{tabular}

cell. The scattering background coming from the X-ray windows is shown in Fig. 2 and is sufficiently low for most sample systems. In addition the windows can be exchanged with different kinds of materials like Kapton or mica and can be reduced to single-pane windows. The size of the outgoing $\mathrm{X}$-ray windows also limits the maximal measurable scattering angle $2 \Theta_{\max }=34.5^{\circ}$. The size of the windows is a compromise between the limited spatial freedom at many instruments and the accessible angular range. This can be a limitation especially for measurements using tender X-ray energies. Thus, the use of higher X-ray energies in the $20-30 \mathrm{keV}$ range is often recommended, which also reduces the extinction of the X-ray beam by the atmosphere inside the cell and decreases the probability for radiation damage (Richter \& Kuzmenko, 2013).

The whole cell concept has been optimized to efficiently perform real-time studies of thin-film formations after doctor blading. A ZUA 2000 applicator (Zehntner GmbH, Sissach, Switzerland) is used for blading, which allows a maximal sample width of $60 \mathrm{~mm}$. The cell mechanics limit the maximal sample length to about $120 \mathrm{~mm}$. The gap width of the applicator can be adjusted between $0 \mu \mathrm{m}$ and $3000 \mu \mathrm{m}$ with a precision of $10 \mu \mathrm{m}$. To optimize the homogeneity, quality and thickness of the thin film it is necessary to adjust the blading speed accordingly. The blading speed is one major parameter for controlling the solution meniscus which is formed in between the applicator and the substrate (Krebs, 2009). Therefore, the applicator is driven by a stepper motor (T5909X2508-B; Nanotec GmbH \& Co. KG, Feldkirchen,
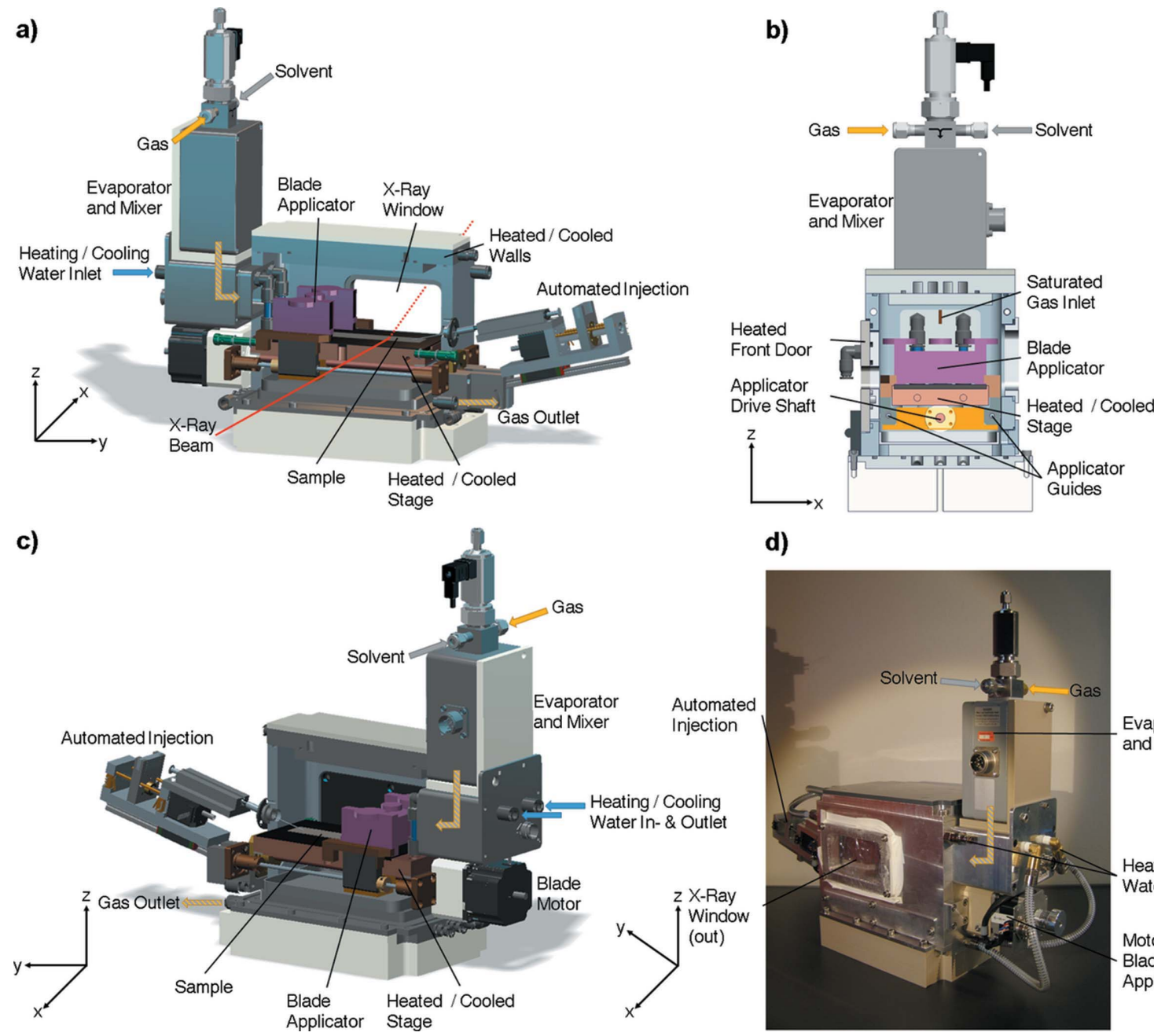

d)

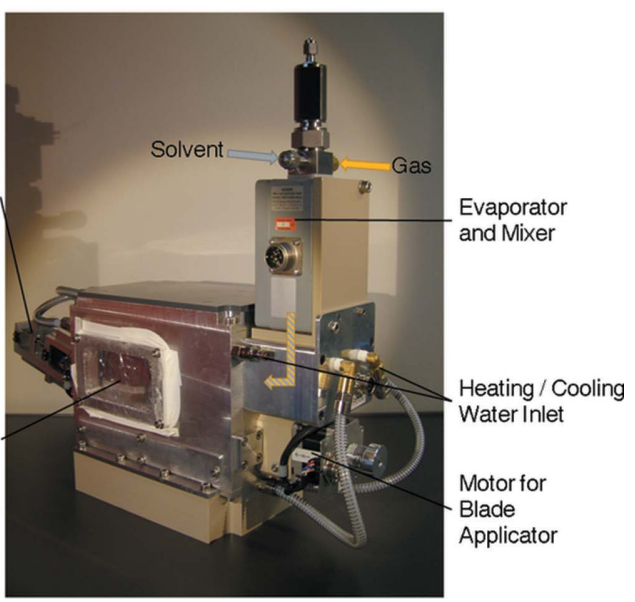

Figure 1

$(a, b, c)$ Technical drawings of the automated in situ cell. Water-, solvent- and gas-hoses as well as optional optical probes are not depicted for clarity. (d) Photograph of the back side of the cell. Most connections (motor cables and heating, gas and water inlets) are removed for clarity. 
Table 2

Summary of the most important specifications of the in situ cell sorted by their occurrence in $\S 2$.

Applicator denotes the applicator of the doctor blade. Aliquot volume is the volume which can be inserted on a substrate (for doctor blading) by the precursor solution insertion system. The heating and cooling range of the sample is given for two heating mediums: pure water and water with additives. Translation denotes the range that the cell can be moved perpendicular to the $\mathrm{X}$-ray beam by an external stage to minimize radiation damages. The last block gives the specifications of the CEM. RT: room temperature.

\begin{tabular}{lll}
\hline Parameter & Minimum & Maximum \\
\hline $2 \Theta\left({ }^{\circ}\right)$ & & 34.5 \\
Sample width $(\mathrm{mm})$ & & 60 \\
Sample length $(\mathrm{mm})$ & & 120 \\
Applicator height $(\mathrm{mm})$ & 0.25 & $3000 \pm 10$ \\
$\begin{array}{l}\text { Blading speed }\left(\mathrm{mm} \mathrm{s}^{-1}\right) \\
\text { Aliquot volume }(\mu \mathrm{l})\end{array}$ & 25 & 35.0 \\
$T_{\text {pure water }}\left({ }^{\circ} \mathrm{C}\right)$ & 3 & 1000 \\
$\left.T_{\text {with additives }}{ }^{\circ} \mathrm{C}\right)$ & -20 & 97 \\
Translation $(\mathrm{mm})$ & 0 & 120 \\
Gas flow $\left(\mathrm{l}_{\mathrm{n}} \mathrm{min}^{-1}\right)$ & 0.0 & 40 \\
Solvent flow $\left(\mathrm{g} \mathrm{h}^{-1}\right)$ & 0 & 1.0 \\
$T_{\text {evaporator }}\left({ }^{\circ} \mathrm{C}\right)$ & $\mathrm{RT}$ & 100 \\
\hline
\end{tabular}

Germany), which allows variable blading speeds from $0.25 \mathrm{~mm} \mathrm{~s}^{-1}$ up to $35 \mathrm{~mm} \mathrm{~s}^{-1}$.

The sample precursor solutions are applied by a motorized syringe system (see Fig. 3) with typical sample volumes between $50 \mu \mathrm{l}$ and $200 \mu \mathrm{l}$ and a maximum amount of $1 \mathrm{ml}$. Since remote control is a necessity for operation at large-scale facilities, both the blading and the sample injection are remote controlled and scriptable, as is the rest of the sample cell (see Fig. 4). For future upgrades, the cell is prepared to have a slotdie applicator installed. This is even closer to industrial printing than doctor blading.
Other important factors for the quality of the coated film is the well defined temperature of the substrate, the atmosphere inside the cell and the solvent used in the precursor solution. For accurate temperature control the sample cell is connected to an external water thermostat, with a Pt100 PTC-thermistor placed inside the copper sample stage. To achieve a homogeneous temperature inside the cell, the sample stage, the front, top and bottom walls and the edges of the cell are heated by a temperated water flow. More details on the temperature homogeneity and stability are given in $\S \mathrm{S} 3$ of the supporting information. Water containing additives limits the achievable temperature range to between $-20^{\circ} \mathrm{C}$ and $120^{\circ} \mathrm{C}$. In normal operation the sample stage and the rest of the sample cell are thermally coupled, but can be decoupled if needed.

In order to avoid radiation damage of the sample the whole cell can be moved up to $40 \mathrm{~mm}$ perpendicular to the X-ray beam by an external translation stage. The cell can also be flushed with gases like helium or nitrogen which decrease the risk of radiation damage on the sample and reduce scattering of the gas phase in the in situ cell. For this purpose the cell is equipped with a mass-flow controller for gases (EL-FLOW Select, F-201CV-1K0-RGD-33-V; Bronkhorst High-Tech BV, AK Ruurlo, The Netherlands) allowing the gas flow to be adjusted in the range between $01_{n} \min ^{-1}$ and $1 l_{n} \min ^{-1}$. This gas-mass-flow controller is part of a controlled evaporator mixer (CEM) device (W-202A-330-K; Bronkhorst High-Tech BV, AK Ruurlo, The Netherlands) which also includes a massflow controller for liquids (MINI CORI-FLOW, M13-RGD33-O-S, Bronkhorst High-Tech BV, AK Ruurlo, The Netherlands) with a flow rate between $0 \mathrm{~g} \mathrm{~h}^{-1}$ and $1 \mathrm{~g} \mathrm{~h}^{-1}$. The liquid is pumped into the in situ cell by pressurizing a filled washing bottle with 1 bar excess pressure. This bottle also acts as a reservoir for the liquid during the experiments. Both the gas and the liquid flows are mixed in the CEM, which consists of a a) No sample

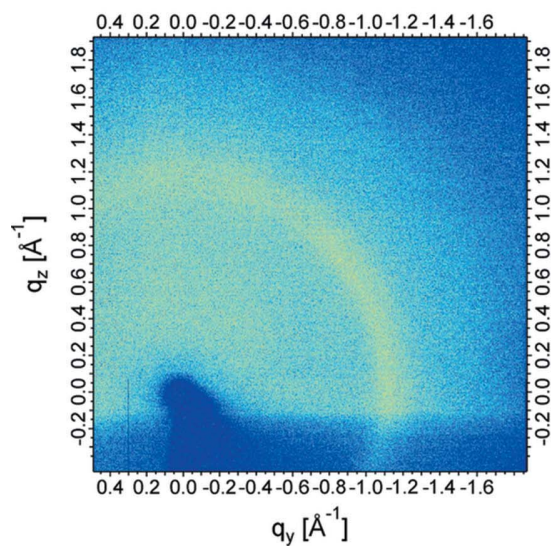

b) Glass substrate

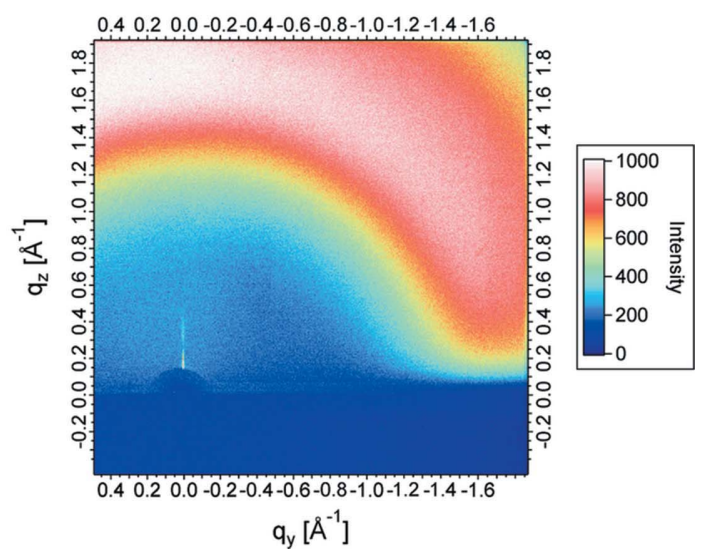

Figure 2

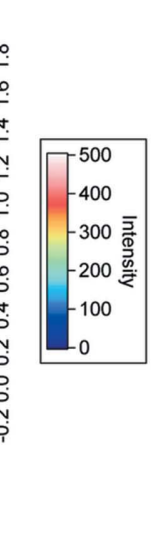

GIWAXS images demonstrating the background signal generated by the scattering of the X-ray windows, the atmosphere inside the in situ cell, and the air in between the cell and the detector. The measured intensities are solid-angle- and polarization-corrected. (a) Background without any sample in the beam. $(b)$ Pure glass substrate measured under grazing-incidence conditions $\left(\alpha_{\mathrm{i}}=0.065^{\circ}\right)$. Both measurements were performed at the P08 beamline (PETRA III, DESY) with an X-ray energy of $25 \mathrm{keV}$, a sample-to-detector distance of $1386.98 \mathrm{~mm}$ and an exposure time of $1 \mathrm{~s}$. The shadowing in (a) below $q_{z} \simeq-0.2 \AA^{-1}$ is caused by the size of the outgoing window. This region of the detector is typically not used during GIWAXS, GISAXS and XRR measurements since it is below the projection of the sample horizon on the detector. 


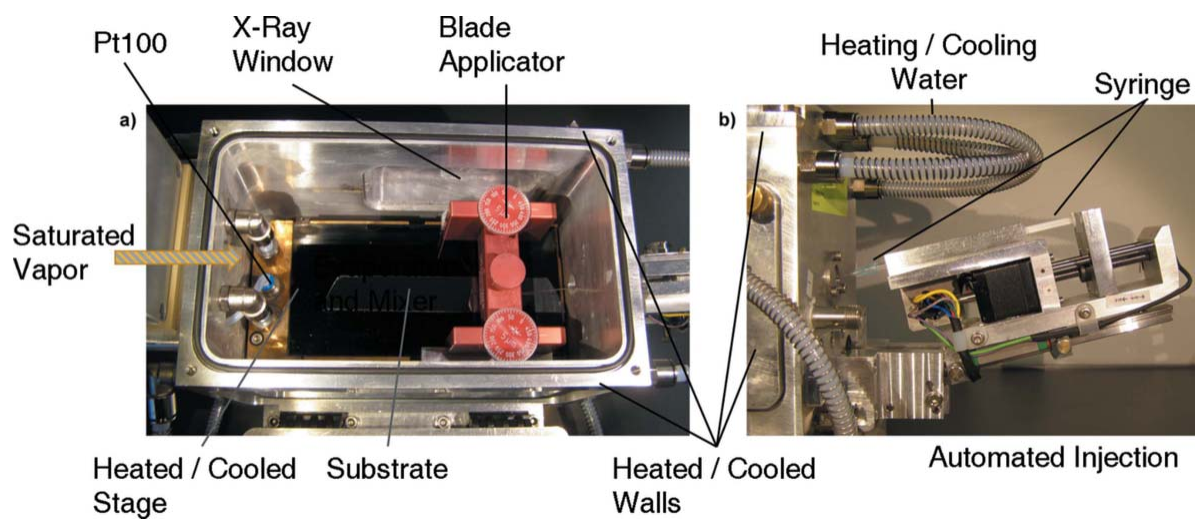

Figure 3

(a) Photograph of the inside of the in situ cell (with top cover removed) showing the doctor blade above a silicon substrate before coating. The sample precursor solution is inserted from the right-hand side via a syringe with a long cannula. (b) Close-up of the sample precursor solution insertion system. experiments of the first $(\$ 3.1)$ and second (\$3.2) example were performed at the P08 beamline at PETRA III (DESY) (Seeck et al., 2012). P08 is well suited for these types of studies as it provides the possibilities to characterize thin films by XRR, GIWAXS and GISAXS measurements. It is equipped with a high-precision six-circle diffractometer which allows for mounting of sample environments with a total weight of up to $15 \mathrm{~kg}$. The GIWAXS experiments at the $\mathrm{P} 08$ beamline were performed using a photon energy of $25 \mathrm{keV}$, a beam size of $0.1 \mathrm{~mm} \times$ $0.1 \mathrm{~mm}$, a frame time of $0.1 \mathrm{~s}$ and an XRD-1621 flat-panel detector (Perkin Elmer Inc., Waltham, USA) with a sample-to-detector distance of $1386.98 \mathrm{~mm}$.

\subsection{In situ doctor blading of $\mathrm{P} 3 \mathrm{HT}: \mathrm{PC}_{61} \mathrm{BM}$}

Doctor blading is a key method for studying thin-film coatings for a large variety of applications. It is perfectly suited for time-resolved studies of the drying kinetics of OPVs. As discussed above, a key necessity for such time-resolved studies on fast-drying thin films is the ability to vary the blading speed over a wide range. This is one main feature discussed in this section.

We chose a well known heterojunction OPV active layer and used a 1.0:1.0 weight ratio of poly(3-hexylthiophen-2,5diyl) (P3HT) (purity $\geq 99 \%$, regioregularity 96.6\%; Merck KGaA, Darmstadt, Germany) and [6,6]-phenyl- $\mathrm{C}_{61}$-butyric acid methyl ester $\left(\mathrm{PC}_{61} \mathrm{BM}\right)$ (purity $\geq 99 \%$, Solenne $\mathrm{BV}$, Groningen, The Netherlands). $30 \mathrm{mg} \mathrm{ml}^{-1}$ of the P3HT:PC 61 BM mixture were dissolved in chlorobenzene (purity $\geq 99.5 \%$; Merck KGaA, Darmstadt, Germany) and a $50 \mu \mathrm{l}$ aliquot was bladed with a blading speed $v_{\mathrm{b}}$ of $7.5 \mathrm{~mm} \mathrm{~s}^{-1}$ on a $\{100\}$ orientated silicon wafer $(20 \mathrm{~mm} \times 80 \mathrm{~mm})$ with a superficial native oxide layer (Siltronic AG, München, Germany). The temperature during the blading process and the measurements was kept constant at $55^{\circ} \mathrm{C}$. The measurements were performed with an angle of incidence of $0.065^{\circ}$, which is in between the critical angles of the substrate $\left(\alpha_{\mathrm{c}, \mathrm{Si}} \simeq\right.$ $\left.0.071^{\circ}\right)$ and the P3HT:PC ${ }_{61} \mathrm{BM}$ layer $\left(\alpha_{\mathrm{c}, \text { layer }} \simeq 0.057^{\circ}\right)($ Henke et al., 1993). The data were reduced to $q_{z}$-cuts using a customized version of the DPDAK software (Benecke et al., 2014) without any further corrections.

During the film drying the diffraction patterns display the rising intensity of the 100 Bragg peak at $q_{z}=3.86 \mathrm{~nm}^{-1}$ which corresponds to the formation of the lamellar stacking of $\mathrm{P} 3 \mathrm{HT}$ (see Fig. 5). Due to the low film crystallinity, higher orders of the lamellar stacking were not resolved. P3HT also exhibits the expected shrinking of the lamellar spacing starting simultaneously with the crystallization of the 100 peak after about $8 \mathrm{~s}$ (see Fig. 5c). As we have shown in our previous work

demonstrated by three different experiments. X-ray scattering 

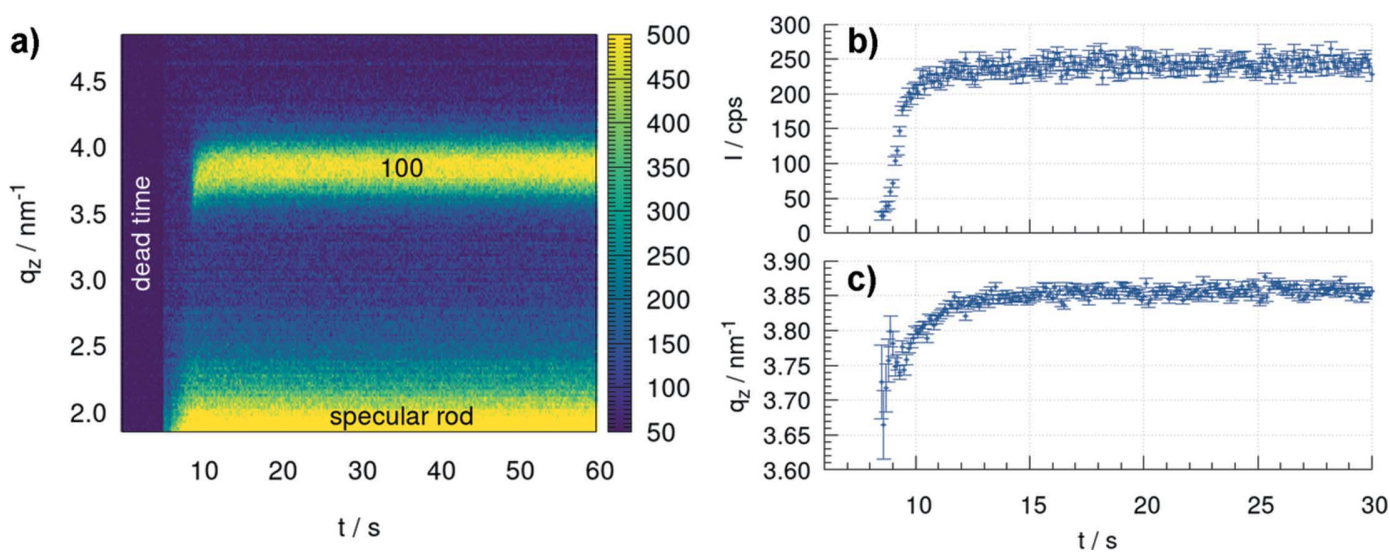

Figure 5

(a) Time-resolved GIWAXS out-of-plane $\left(q_{z}\right)$ profiles at $q_{y}=0$ of doctor bladed P3HT:PC ${ }_{61} \mathrm{BM}$. The beam is covered in the first $5 \mathrm{~s}$ by the moving applicator (labeled as dead-time). The 100 peak around $q_{z}=3.8 \mathrm{~nm}^{-1}$ rises during the drying process. The high intensity at small $q$ values corresponds to the tails of the specular rod. Panels $(b)$ and $(c)$ display the change of the integrated intensity and the peak center of the 100 Bragg peak over time, respectively.

(Güldal et al., 2016a; Kassar et al., 2016), this shrinking process is due to the evaporation of solvent incorporated in the P3HT matrix.

As this example evinces, there is a twofold temporal requirement for studying thin-film drying processes. Both are met by the in situ sample cell: firstly, typical frame times of $1 \mathrm{~s}$ or less are needed to resolve thin-film drying kinetics. This can easily be achieved using synchrotron radiation since the time resolution is not limited by the in situ cell but by the photon flux in the X-ray beam. Secondly, there is a distinct dead-time at the beginning of each drying process in which no diffraction patterns can be recorded since the applicator of the doctor blade blocks the X-ray beam during its movement. The time of blocking depends on the blading speed; in this example the dead-time is as low as $5 \mathrm{~s}$. Since the blading speed can be varied freely by changing the frequency of the corresponding stepper motor, the in situ cell allows fast drying processes to be studied.

\subsection{In situ solvent vapor annealing of DRCN5T:PC ${ }_{71} B M$}

In many thin-film applications the post-coating SVA of thin films represents an essential step for optimizing characteristics and performance (Deng et al., 2018; Heo et al., 2017). It was recently demonstrated that the PCE of DRCN5T:PC ${ }_{71} \mathrm{BM}$ was increased from $3.23 \%$ to $6.22 \%$ after annealing with chloroform (Min et al., 2016) due to crystallization of the so-called small-molecule donor $2,2^{\prime}-\left\{\left[3,3^{\prime \prime \prime \prime}, 3^{\prime \prime \prime \prime}, 4^{\prime}\right.\right.$-tetraoctyl $\left(2,2^{\prime}: 5^{\prime}, 2^{\prime \prime}\right.$ : $5^{\prime \prime}, 2^{\prime \prime \prime}: 5^{\prime \prime \prime}, 2^{\prime \prime \prime \prime}$-quinquethiophene $)-5,5^{\prime \prime \prime \prime}$-diyl $]$ bis $[(Z)$-methylidyne(3-ethyl-4-oxo-5,2-thiazolidinediylidene)]\}bis-propanedinitrile (DRCN5T). Thus, DRCN5T:PC 71 BM was chosen to demonstrate the SVA capabilities of the in situ cell.

DRCN5T (purity $\geq 99 \%$; 1-Material Inc., Dorval, Canada) and $\mathrm{PC}_{71} \mathrm{BM}$ (purity $\geq 99 \%$; Solenne BV, Groningen, The Netherlands) were dissolved in chlorobenzene (purity $\geq$ 99.5\%; Merck KGaA, Darmstadt, Germany) with a 1.0:0.8 weight ratio and a concentration of $15 \mathrm{mg} \mathrm{ml}^{-1}$ of the mixture. Aliquots of $80 \mu \mathrm{l}$ of this solution were spin-coated in advance on glass substrates $(1.0$ inch $\times 1.0$ inch; Hans Weidner $\mathrm{GmbH}$, Nürnberg, Germany). During the experiment the samples were annealed by chloroform saturated nitrogen with close to $100 \%$ relative saturation. The experiment was performed at the P08 beamline (DESY) with the same experimental parameters used for the experiment described in $\$ 3.1$, except the cell temperature which was set to $22^{\circ} \mathrm{C}$.

The kinetics of the SVA process of DRCN5T:PC ${ }_{71} \mathrm{BM}$ are very complex and its details go beyond the scope of this article. Nevertheless, comparing the scattering patterns before and after $200 \mathrm{~s}$ annealing it becomes obvious that the nonannealed sample shows low crystallinity, with a high mosaicity and preferred edge-on orientation (see Fig. 6a). During annealing with chloroform, which is a good solvent for both DRCN5T and $\mathrm{PC}_{71} \mathrm{BM}$, DRCN5T crystallizes as expected from the literature (Sun et al., 2014; Min et al., 2016) and sharp Bragg peaks can be observed (see Fig. 6b). This crystallization leads to the increase in PCE by enhancing the conductivity of the photoactive layer (Min et al., 2016). Therefore, determination of the crystalline structure is important for the understanding and design of high-efficiency OPV. Our in situ cell allows such experiments with a high degree of reproducibility and the option for time-resolved studies.

\subsection{Hydration of lipid multilayers}

Membranes of biological cells are built by a mixture of amphiphatic lipids forming a bilayer, with phospholipids being the most prevalent lipid class (Copper, 2000). Thus, phospholipids like 1,2-dimyristoyl-sn-glycero-3-phosphocholine (DMPC) are widely used as model systems for studying the structure and dynamics of biological membranes (Kučerka et al., 2005; Nagle \& Tristram-Nagle, 2000; Salditt \& Aeffner, 2016; Lautner et al., 2017; Jing et al., 2009; Salditt et al., 2002; Katsaras \& Watson, 2000). Examples for such model systems are solid supported phospholipid multilayers consisting of periodically repeating lipid bilayers separated by thin water layers. 
a) as bladed

b) after SVA

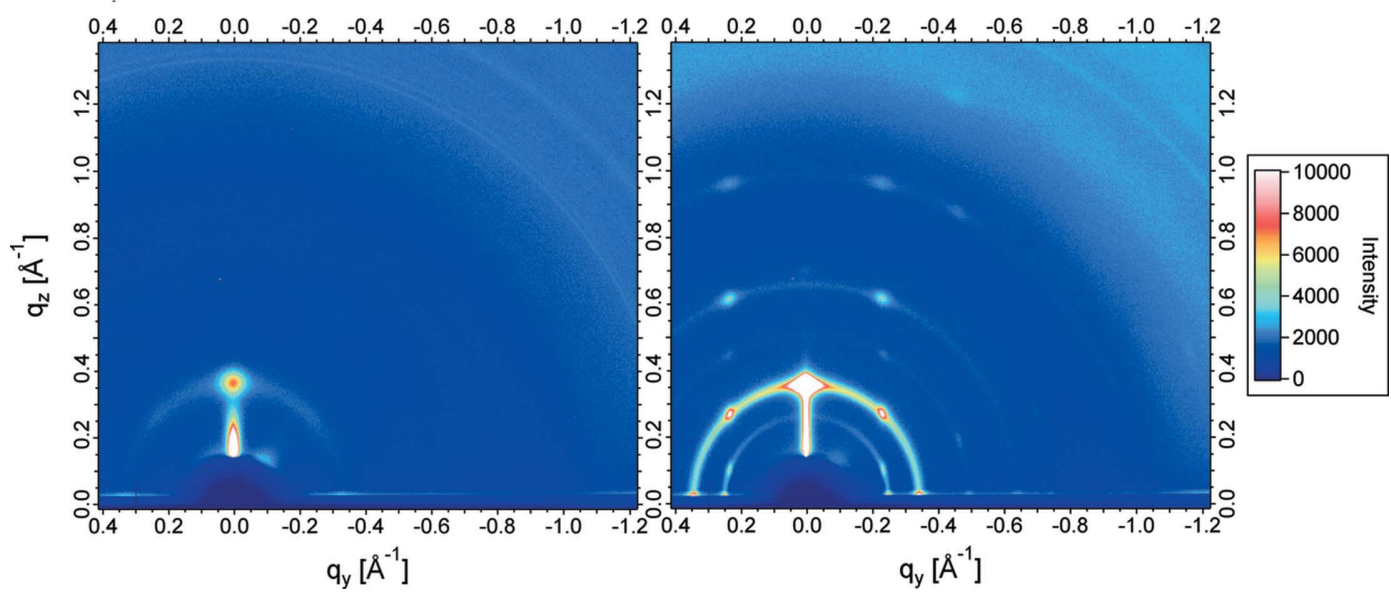

Figure 6 $\mathrm{q}_{\mathrm{y}}\left[\AA^{-1}\right]$

Cutout of the polarization- and solid-angle-corrected detector images (GIWAXS) of a DRCN5T:PC ${ }_{71} \mathrm{BM}_{\text {thin }}$ film $(a)$ before annealing and $(b)$ after annealing with chloroform. Both images were measured for $30 \mathrm{~s}$ at the P08 beamline (PETRA III, DESY).

To mimic the state of biological membranes, these multilayers need to be hydrated. This has a significant impact on the layered structure, especially on the thickness of the intermediate water layer and the crystalline phase of the liquid crystal. Thus, the first main focus in this example is that the humidity can be controlled precisely, especially close to $100 \%$ relative humidity. To achieve the desired hydrations the sample cell is typically heated slightly above the phase transition temperature of the lipid (gel phase $\mathrm{L}_{\beta}^{\prime}$ to the liquid crystalline $\mathrm{L}_{\alpha}$-phase). Here, the liquid crystalline $\mathrm{L}_{\alpha}$ phase of DMPC was hydrated at $30^{\circ} \mathrm{C}$ (main phase transition temperature $T_{\mathrm{m}} \simeq 24^{\circ} \mathrm{C}$ ). In the $\mathrm{L}_{\alpha}$ phase the interplanar $(d$-)spacing, which corresponds to the bilayer stacking distance, strongly depends on the relative humidity of the surrounding atmosphere. Full hydration of DMPC at $30^{\circ} \mathrm{C}$ is indicated by a $d$-spacing of $62.7 \AA\left(q=0.1002 \AA^{-1}\right)($ Kučerka et al., 2005).

The second focus of this example is that time-resolved XRR, GISAXS and GIWAXS can be and have been performed interchangeably during the hydration process. This will be discussed in the following paragraphs starting with GIWAXS. The first GIWAXS frame of the hydration study is performed without any air or water flux into the in situ cell (ambient humidity). Starting with the second frame, the sample was hydrated by a constant flux of water-saturated air: $13 \mathrm{~g} \mathrm{~h}^{-1}$ of water were evaporated and mixed with $1 \mathrm{l}_{\mathrm{n}} \min ^{-1}$ air to achieve close to $100 \%$ relative humidity. Before hydration, the first-order Bragg peak related to the bilayer stacking distance is at $q=0.122 \AA^{-1}$ corresponding to $d=$ $51.5 \AA$ (see Fig. 7). After starting the hydration, water is incorporated into the liquid crystals structure which results in an increase of the $d$-spacing. After $30 \mathrm{~min}$ a splitting of the 001 Bragg reflection is observed (see Fig. 7). This signature is attributed to an intermediate bimodal state in which the sample consists of two states: one with higher hydration and one with lower hydration. With increasing time, the hydration of both states increases and converges to the final fully hydrated state after $11.5 \mathrm{~h}$. It is thus evident that full hydration can be reached using the in situ cell.
The cell presented here can also be used for XRR studies as it is shown for a DMPC multilayer upon hydration at a temperature of $30^{\circ} \mathrm{C}$. In good agreement with the GIWAXS data, the sample reveals the typical Bragg peaks corresponding to the lipid-bilayer stacking (see Fig. 8). For timeresolved hydration studies, XRR and GIWAXS can be used consecutively during different or in the course of a single hydration series. Here, GIWAXS typically provides a better time resolution compared with XRR.

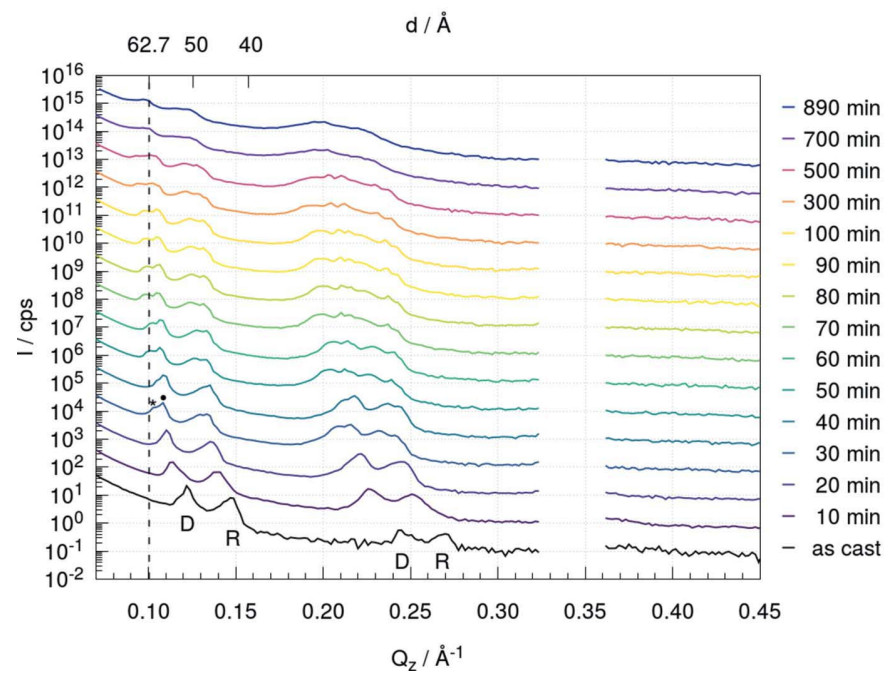

Figure 7

Time-resolved GIWAXS $q_{z}$-cuts (frame time $10 \mathrm{~min}$ ) before (black curve) and during hydration (water flux $13.0 \mathrm{~g} \mathrm{~h}^{-1}$, colored curves) of the phospholipid DMPC. The curves are shifted upwards for better visibility. The gap around $0.35 \AA^{-1}$ corresponds to the dead stripes of the used Pilatus 300k detector. The graph displays first- and second-order Bragg peaks corresponding to the bilayer stacking. Each diffraction order is split into two peaks, due to scattering of the direct beam (labeled D), and scattering of the reflected beam (labeled R). The dashed line marks the peak position for the scattering of the direct beam when the layers are fully hydrated. After $30 \mathrm{~min}$ until full hydration is reached after around 700 min the sample is in a bimodal state consisting of a state with lower (labeled $\bullet$ ) and one with higher hydration (labeled *). 


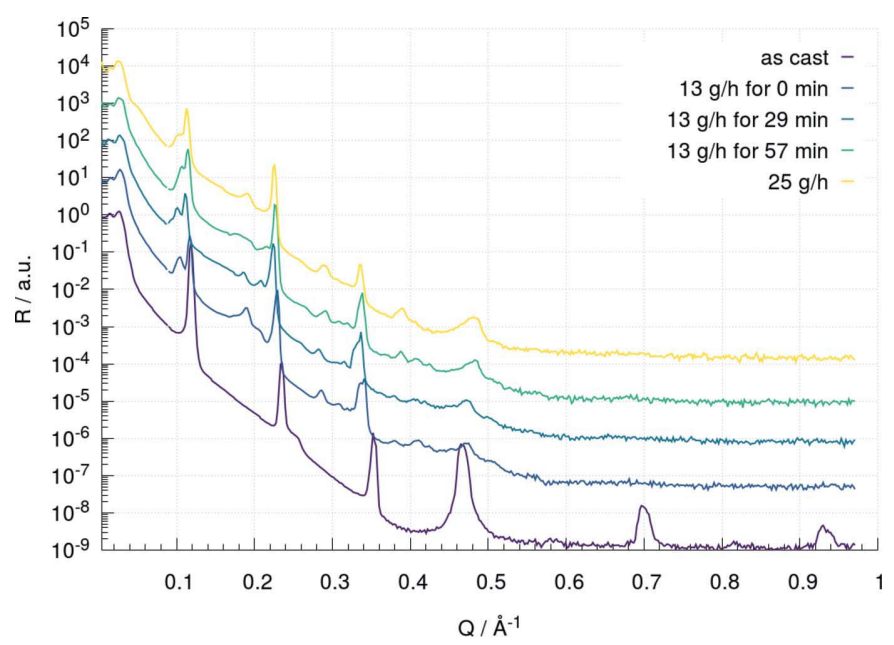

Figure 8

Time-resolved XRR of DMPC. The as-cast measurement was performed at ambient humidities (violet curve). Starting with the second measurement, the water flux was constant at $13.0 \mathrm{~g} \mathrm{~h}^{-1}$ (colored curves). Above $1 \AA^{-1}$ no further Bragg peak is present. The curves are shifted upwards for increased clarity.

The GIWAXS measurements were performed in-house at the Versatile Advanced X-ray Scattering instrumenT ERlangen (VAXSTER) using a wavelength of $1.341 \AA$ and a sample-to-detector distance of $418.2 \mathrm{~mm}$. The incidence angle was set to $0.170^{\circ}$ which is in between the critical angle of the Si substrate ( $\{100\}$ orientated $\mathrm{Si} / \mathrm{SiO}_{2}$ wafer) and the DMPC layer $\left(\alpha_{\text {c,layer }} \simeq 0.134^{\circ}\right)$ (Henke et al., 1993). The XRR measurements were performed at the ID10 EH1 beamline (ESRF) using an X-ray energy of $22 \mathrm{keV}$. For both measurement series, $20 \mathrm{mg} \mathrm{ml}^{-1}$ of DMPC (purity of fatty acids: $100 \%$; Lipoid $\mathrm{GmbH}$, Ludwigshafen, Germany) were dissolved in a mixture of methanol (purity $\geq 99.98 \%$; Carl Roth $\mathrm{GmbH}$, Karlsruhe, Germany) and chloroform (purity $\geq 99.9 \%$; Carl Roth GmbH, Karlsruhe, Germany), which was doctor bladed beforehand onto the Si substrate.

\section{Conclusion}

We have developed and constructed a highly flexible and portable sample cell for GIWAXS, GISAXS and XRR measurements with the main focus being to enable a wide variety of real-time applications both at synchrotron beamlines and laboratory instruments. Examples for possibilities to perform real-time studies were given: the structure formation during doctor blading of $\mathrm{P} 3 \mathrm{HT}: \mathrm{PC}_{61} \mathrm{BM}$, crystallization during SVA of a DRCN5T:PC ${ }_{71} \mathrm{BM}$ thin film, and the hydration of multilayers of the phospholipid DMPC. Emphasis was also placed on providing a high degree of automation, a highly controllable atmosphere and a high thermal stability, which was realized by water-heated sample stage and walls. It was discussed that the blading speed can be varied from $0.25 \mathrm{~mm} \mathrm{~s}^{-1}$ up to $35 \mathrm{~mm} \mathrm{~s}^{-1}$ to optimize the blading process for homogeneity of the resulting thin films and to minimize dead-times before the first measurement frame caused by the blocking of the beam during the applicator movement. SVA and hydration experiments showed that the relative solvent or water saturation of the gas phase inside the cell can be controlled precisely and that full sample hydration can be achieved. The interchangeability of time-resolved grazingincidences techniques with time-resolved X-ray reflectivity provides three common analysis methods in the field of thinfilm analysis. In addition the cell is prepared to add secondary probes in the future, with the focus on optical techniques, like photoluminescence spectroscopy and white-light reflectometry.

\section{Acknowledgements}

The authors thank Herbert Lang and Jürgen Grasser from the workshop of the Institute for Crystallography and Structural Physics (ICSP) at FAU for the construction of the in situ sample cell. We acknowledge DESY (Hamburg, Germany), a member of the Helmholtz Association HGF, for the provision of experimental facilities. Parts of this research were carried out at PETRA III and we would like to thank Milena Lippmann, Uta Rüth, Oliver Seeck and René Kirchhof for assistance in using the P08 beamline and the chemical laboratory of the Deutsches Elektronen-Synchrotron (DESY). We acknowledge the European Synchrotron Radiation Facility (ESRF) for provision of synchrotron radiation facilities and we would like to thank Oleg Konovalov for assistance in using beamline ID10 and Harald Müller for his support at the chemical laboratory.

\section{Funding information}

The authors gratefully acknowledge the funding of the Deutsche Forschungsgemeinschaft (DFG) through the 'Cluster of Excellence Engineering of Advanced Materials (EAM)'. MB, CB, JW, TS, TZ and TU thank the research training group GRK 1896 'In situ Microscopy with Electrons, X-rays and Scanning Probes', the research unit FOR 1878 'Functional Molecular Structures on Complex Oxide Surfaces', the German Federal Ministry of Education and Research (BMBF, project numbers: 05K16WEB, 05K16WE1) and the DFG (INST 90/825-1 FUGG, INST 90/751-1 FUGG, INST 90/827-1 FUGG) for their funding. SL and CJB are gratefully thankful for financial support provided by the DFG in the framework of SFB 953 'Synthetic Carbon Allotropes'. CJB gratefully acknowledges the 'Solar Energy goes Hybrid' Initiative (SolTech) and the 'Solar Factory of the Future' as part of the Energy Campus Nürnberg (EnCN), which is supported by the Bavarian State Government (FKZ 20.23410.5-4-5).

\section{References}

Bartelt, J. A., Beiley, Z. M., Hoke, E. T., Mateker, W. R., Douglas, J. D., Collins, B. A., Tumbleston, J. R., Graham, K. R., Amassian, A., Ade, H., Fréchet, J. M. J., Toney, M. F. \& McGehee, M. D. (2013). Adv. Eng. Mater. 3, 364-374.

Benecke, G., Wagermaier, W., Li, C., Schwartzkopf, M., Flucke, G., Hoerth, R., Zizak, I., Burghammer, M., Metwalli, E., MüllerBuschbaum, P., Trebbin, M., Förster, S., Paris, O., Roth, S. V. \& Fratzl, P. (2014). J. Appl. Cryst. 47, 1797-1803. 
Brabec, C. J. \& Durrant, J. R. (2008). MRS Bull. 33, 670-675.

Copper, G. M. (2000). The Cell: A Molecular Approach, 2nd ed. American Society of Microbiology.

Deng, W., Gao, K., Yan, J., Liang, Q., Xie, Y., He, Z., Wu, H., Peng, X. \& Cao, Y. (2018). Appl. Mater. Interfaces, 10, 8141-8147.

Doshi, D. A., Gibaud, A., Goletto, V., Lu, M., Gerung, H., Ocko, B., Han, S. M. \& Brinker, C. J. (2003). J. Am. Chem. Soc. 125, 1164611655.

Ferrarese Lupi, F., Giammaria, T. J., Seguini, G., Laus, M., Dubček, P., Pivac, B., Bernstorff, S. \& Perego, M. (2017). Appl. Mater. Interfaces, 9, 11054-11063.

Fuwen, Z., Chunru, W. \& Xiaowei, Z. (2018). Adv. Eng. Mater. 109, 1703147.

Gu, X., Reinspach, J., Worfolk, B. J., Diao, Y., Zhou, Y., Yan, H., Gu, K., Mannsfeld, S., Toney, M. F. \& Bao, Z. (2016). Appl. Mater. Interfaces, 8, 1687-1694.

Güldal, N. S., Berlinghof, M., Kassar, T., Du, X., Jiao, X., Meyer, M., Ameri, T., Osvet, A., Li, N., Destri, G. L., Fink, R. H., Ade, H., Unruh, T. \& Brabec, C. J. (2016b). J. Mater. Chem. A, 4, 1613616147.

Güldal, N. S., Kassar, T., Berlinghof, M., Ameri, T., Osvet, A., Pacios, R., Li Destri, G., Unruh, T. \& Brabec, C. J. (2016a). J. Mater. Chem. C. 4, 2178-2186.

Güldal, N. S., Kassar, T., Berlinghof, M., Unruh, T. \& Brabec, C. J. (2017). J. Mater. Res. 32, 1855-1879.

Gunkel, I., Gu, X., Sun, Z., Schaible, E., Hexemer, A. \& Russell, T. P. (2015). J. Polym. Sci. Part B Polym. Phys. 54, 331-338.

Henke, B., Gullikson, E. \& Davis, J. (1993). At. Data Nucl. Data Tables, 54, 181-342.

Heo, Y.-J., Jung, Y.-S., Hwang, K., Kim, J.-E., Yeo, J.-S., Lee, S., Jeon, Y.-J., Lee, D. \& Kim, D.-Y. (2017). Appl. Mater. Interfaces, 9, 3951939525.

Hu, S., Dyck, O., Chen, H., Hsiao, Y., Hu, B., Duscher, G., Dadmun, M. \& Khomami, B. (2014). RSC Adv. 4, 27931-27938.

Jiang, Z., Lee, D. R., Narayanan, S., Wang, J. \& Sinha, S. K. (2011). Phys. Rev. B, 84, 075440.

Jing, H. Y., Hong, D. H., Kwak, B. D., Choi, D. J., Shin, K., Yu, C.-J., Kim, J. W., Noh, D. Y. \& Seo, Y. S. (2009). Langmuir, 25, 4198-4202.

Kamata, Y., Parnell, A. J., Gutfreund, P., Skoda, M. W. A., Dennison, A. J. C., Barker, R., Mai, S., Howse, J. R., Ryan, A. J., Torikai, N., Kawaguchi, M. \& Jones, R. A. L. (2014). Macromolecules, 47, 86828690.

Kassar, T., Güldal, N. S., Berlinghof, M., Ameri, T., Kratzer, A., Schroeder, B. C., Destri, G. L., Hirsch, A., Heeney, M., McCulloch, I., Brabec, C. J. \& Unruh, T. (2016). Adv. Energy Mater. 6, 1502025.

Katsaras, J. \& Watson, M. J. (2000). Rev. Sci. Instrum. 71, 17371739.

Kirschner, J., Will, J., Rejek, T. J., Portilla, L., Berlinghof, M., Schweizer, P., Spiecker, E., Steinrück, H., Unruh, T. \& Halik, M. (2017). Adv. Mater. Interfaces, 4, 1700230.

Krebs, F. C. (2009). Solar Energy Mater. Solar Cells, 93, 394-412.

Kučerka, N., Liu, Y., Chu, N., Petrache, H. I., Tristram-Nagle, S. \& Nagle, J. F. (2005). Biophys. J. 88, 2626-2637.

Lautner, L., Pluhackova, K., Barth, N. K., Seydel, T., Lohstroh, W., Böckmann, R. A. \& Unruh, T. (2017). Chem. Phys. Lipids, 206, 2842.

Lilliu, S., Agostinelli, T., Hampton, M., Pires, E., Nelson, J. \& Macdonald, J. E. (2012). Energy Procedia, 31, 60-68.
Liu, F., Ferdous, S., Schaible, E., Hexemer, A., Church, M., Ding, X., Wang, C. \& Russell, T. P. (2015). Adv. Mater. 27, 886-891.

Manley, E. F., Strzalka, J., Fauvell, T. J., Jackson, N. E., Leonardi, M. J., Eastham, N. D., Marks, T. J. \& Chen, L. X. (2017). Adv. Mater. 29, 1703933.

Min, J., Güldal, N. S., Guo, J., Fang, C., Jiao, X., Hu, H., Heumüller, T., Ade, H. \& Brabec, C. J. (2017). J. Mater. Chem. A, 5, 18101-18110.

Min, J., Jiao, X., Sgobba, V., Kan, B., Heumüller, T., Rechberger, S., Spiecker, E., Guldi, D. M., Wan, X., Chen, Y., Ade, H. \& Brabec, C. J. (2016). Nano Energy, 28, 241-249.

Müller-Buschbaum, P. (2014). Adv. Mater. 26, 7692-7709.

Nagle, J. F. \& Tristram-Nagle, S. (2000). Biochim. Biophys. Acta, 1469, 159-195.

Peetla, C., Stine, A. \& Labhasetwar, V. (2009). Mol. Pharm. 6, 1264 1276.

Pistor, P., Mainz, R., Heinemann, M. D., Unold, T. \& Scheer, R. (2016). Advanced Characterization Techniques for Thin Film Solar Cells, Vol. 1, pp. 441-467. Wiley-VCH.

Pröller, S., Liu, F., Zhu, C., Wang, C., Russell, T. P., Hexemer, A., Müller-Buschbaum, P. \& Herzig, E. M. (2015). Adv. Energy Mater. 6, 1501580.

Pröller, S., Moseguí González, D., Zhu, C., Schaible, E., Wang, C., Müller-Buschbaum, P., Hexemer, A. \& Herzig, E. M. (2017). Rev. Sci. Instrum. 88, 066101.

Richter, A. G. \& Kuzmenko, I. (2013). Langmuir, 29, 5167-5180.

Roth, S. V. (2016). J. Phys. Condens. Matter, 28, 403003.

Salditt, T. \& Aeffner, S. (2016). Semin. Cell. Dev. Biol. 60, 65-77.

Salditt, T., Li, C., Spaar, A. \& Mennicke, U. (2002). Eur. Phys. J. E, 7, 105-116.

Sanyal, M., Schmidt-Hansberg, B., Klein, M. F. G., Colsmann, A., Munuera, C., Vorobiev, A., Lemmer, U., Schabel, W., Dosch, H. \& Barrena, E. (2011). Adv. Energy Mater. 1, 363-367.

Seeck, O. H., Deiter, C., Pflaum, K., Bertam, F., Beerlink, A., Franz, H., Horbach, J., Schulte-Schrepping, H., Murphy, B. M., Greve, M. \& Magnussen, O. (2012). J. Synchrotron Rad. 19, 30-38.

Soltani, R., Katbab, A. A., Sytnyk, M., Yousefi Amin, A. A., Killilea, N., Berlinghof, M., Ahmadloo, F., Osvet, A., Unruh, T., Heiss, W. \& Ameri, T. (2017). Sol. RRL, 1, 1700043.

Søndergaard, R., Hösel, M., Angmo, D., Larsen-Olsen, T. T. \& Krebs, F. C. (2012). Mater. Today, 15, 36-49.

Steinrück, H. G., Will, J., Magerl, A. \& Ocko, B. M. (2015). Langmuir, 31, 11774-11780.

Sun, K., Xiao, Z., Hanssen, E., Klein, M. F. G., Dam, H. H., Pfaff, M., Gerthsen, D., Wong, W. W. H. \& Jones, D. J. (2014). J. Mater. Chem. $A, 2,9048-9054$.

Tang, C., Tracz, A., Kruk, M., Zhang, R., Smilgies, D.-M., Matyjaszewski, K. \& Kowalewski, T. (2005). J. Am. Chem. Soc. 127, 6918-6919.

Teixeira, V., Feio, M. J. \& Bastos, M. (2012). Prog. Lipid Res. 51, 149177.

Wang, T., Dunbar, A. D. F., Staniec, P. A., Pearson, A. J., Hopkinson, P. E., MacDonald, J. E., Lilliu, S., Pizzey, C., Terrill, N. J., Donald, A. M., Ryan, A. J., Jones, R. A. L. \& Lidzey, D. G. (2010). Soft Matter, 6, 4128-4134.

Wernecke, J. (2016). PhD thesis, University of Lübeck, Germany.

Will, J., Hou, Y., Scheiner, S., Pinkert, U., Hermes, I. M., Weber, S. A., Hirsch, A., Halik, M., Brabec, C. \& Unruh, T. (2018). Appl. Mater. Interfaces, 10, 5511-5518. 